\title{
ALSA and PISA Quantifiable Tool for Diabetic Patients: A Clinical Study
}

\author{
YASHBIR SINGH RAGHAV', ABHINAV BHASKER², ABHISHEK SHARMA³
}

BACKGROUND: Diabetes is a well known risk factor for Periodontitis and the severity of the periodontal disease is often represented as non-continuous variables that quantify the amount of affected periodontal tissue in partial manner. So, Attachment Loss Surface Area (ALSA) and the Periodontal Inflamed Surface Area (PISA) Index have been introduced in order to find out diseased condition in true sense.

AIM: To find out comparison between diabetic and non diabetic patients by using the Attachment Loss Surface Area (ALSA) and the Periodontal Inflamed Surface Area (PISA) Index.

MATERIALS AND METHOD: The study was done in department of Periodontology and Implantology among 6o diabetic and 40 non diabetic patients who attended the OPD of general hospital. Clinical examination with ALISA, PISA and Plaque Index was recorded and collected data was subject to statistical analysis.

RESULTS: It was found that no statistical difference exists between both of the groups. $(\mathrm{p}<0.05)$

CONCLUSION: It was concluded through this study that though as such no difference was found but ALISA and PISA both the parameters can be used to find out the progress of periodontal condition.

KEYWORDS: Diabetic, Periodontitis, Dental plaque, Attachment Loss Surface Area (ALSA) Index, Periodontal Inflamed Surface Area (PISA) Index

\section{INTRODUCTION}

Worldwide Type 2 diabetes mellitus accounting for $90-95 \%$ of all the cases as diabetes is the second most common metabolic disorder in human. ${ }^{1}$ Diabetes is a clear risk factor for Periodontitis which is defined as "an infectious disease resulting in inflammation within the supporting tissues of the teeth, progressive attachment loss and bone loss." ${ }^{2,3}$

There are various risk factors which are associated with periodontal diseases like systemic disorders and conditions, environmental, physical and psychosocial factors. ${ }^{4}$ Many of the researchers revealed the severity of the periodontal disease in the form of non-continuous variables such as mild, moderate, severe etc. But in actual form it doesn't quantify the amount of affected periodontal tissue.

Henceforth continuous variables such as mean probing pocket depth or mean clinical attachment level has been used but they also partly addressed the diseased condition. ${ }^{5,6}$

To overcome this issue Hujoel et al. gave the classification that quantified the total surface area of attachment loss later on which was referred as Attachment Loss Surface Area (ALSA). ${ }^{7}$
Even Nesse et al. also recognized the another important parameter which is known as the Periodontal Inflamed surface Area (PISA) that quantifies the systemic burden of the periodontal disease. ${ }^{5}$

Though the literature is replete with the studies on the prevalence of periodontal diseases among diabetic patients but there is a dearth of literature regarding quantification or burden of periodontal disease and related conditions among diabetic patients. It's been said that the condition of periodontal disease can quantify in actual terms by using ALSA or PISA. Therefore, attempt has been made to conduct a study to analyze the severity of Generalized Chronic Periodontitis expressed in terms of ALSA and PISA in patients with and without Type 2 Diabetes mellitus.

\section{METHODOLOGY}

The study was conducted among 100 successive patients in the department of Periodontology and Implantology. The ethical clearance was taken from Institutional Ethical and informed consent was obtained from the study participants. Out of 100 patients; 60 patients with Type 2 diabetes with more than 3 years duration from the OPD of attached general hospital, and 40 non-diabetic 
patients from the OPD of the Dept. of Periodontology, who fulfilled the inclusion criteria were included in this study. Patients with age of 30 to 60 years with chronic generalized Periodontitis were included and pregnant ,patients with other systemic or acute infectious conditions were excluded from the study.

\section{Clinical examination:}

1. Plaque Index (PI, Silness and Loe, 1964) ${ }^{8}$

All teeth were examined at 4 sites each (distofacial, facial, mesio-facial, lingual/palatal) and were scored as follows

Score o: No plaque

Score 1: Plaque not visible to the naked eye, detected by explorer

Score 2: Thin to moderate accumulation of soft deposits within the gingival pocket or on tooth, visible to the naked eye

Score 3: Abundance of soft matter within gingival pocket or on tooth surface and margin, interdental area stuffed with soft debris

Calculation: Plaque index for a tooth $=$ Total score from 4 areas/ 4

Pl I = Total Plaque indices for all teeth / No. of teeth examined

\section{Interpretation:}

o: Excellent oral hygiene

o.1 to 0.9: Good oral hygiene

1.0 to 1.9: Fair oral hygiene

2.o to 3.0: Poor oral hygiene

2. Bleeding on Probing (BOP): For every tooth starting from second molar, the probe was inserted gently into the gingival sulcus at six sites per tooth (Mesiobuccal, Midbuccal, Distobuccal, Mesiolingual, Midlingual, and Distolingual). The appearance of the bleeding at each site indicated a positive score. The total number of bleeding sites per tooth was thus recorded for every tooth except the third molar.

3. Clinical Attachment Level (CAL): Clinical Attachment Level was measured from the Cemento - Enamel Junction (CEJ) to the base of the pocket in millimeter using Williams Periodontal Probe. Three measurements were made on the buccal aspect and three on the lingual aspect of each tooth - total of six sites per tooth (Mesiobuccal, Midbuccal, Distobuccal, Mesiolingual, Midlingual and Distolingual).
4. Recession: Gingival recession, if present, was measured from Cemento -Enamel Junction (CEJ) to the gingival margin (Location of Gingival Margin LGM).

5. Attachment Loss Surface Area (ALSA), Periodontal Epithelial Surface Area (PESA) and Periodontal Inflamed Surface Area (PISA):5,6 These parameters were derived from Clinical attachment level (CAL), recession and bleeding on probing (BOP) measurements. Excel Spreadsheets that are specially designed for this purpose were downloaded and utilized. To calculate the ALSA, the linear probing measurements, from the cemento-enamel junction (CEJ) to the bottom of the pocket (i.e. CAL), around a particular tooth are fed in the respective Excel cells. Based on the formula function already fed on the excel sheet, these measurements were transformed into the ALSA for that particular tooth. Summing up the individual ALSA scores for the teeth provided the total ALSA score for the patient.

To calculate the PESA, the Recession Surface Area (RSA) was subtracted from ALSA. Since ALSA= PESA + RSA, it was deducted that ALSA - RSA = PESA. To calculate the PESA there are three arithmetical possibilities, depending on the location of the gingival margin (LGM):

1. When LGM is below CEJ, RSA > 0 and PPD < CAL. Thus PESA < ALSA. Therefore PESA = ALSARSA

2. When LGM is exactly at CEJ, PPD = CAL and RSA $=0$.

Therefore PESA = ALSA

3. When LGM is above CEJ, PPD > CAL and hence PESA > ALSA.

To calculate PISA, the inflamed part of the PESA, the following steps were followed in the Excel spreadsheet available for this purpose.

1. When the CAL measurements at six sites per tooth are fed in the Excel spreadsheet, the computer calculates the mean CAL for each particular tooth. This is automatically transformed using the appropriate formula for the translation of linear CAL measurements to the ALSA for that specific tooth.

2. When the recession measurements at six sites per tooth are fed in appropriate cells, the computer calculates the mean recession for each 
particular tooth. This is automatically entered into the appropriate formula for the translation of linear recession measurements to the RSA for that specific tooth.

3. The computer generates the PESA of a particular tooth based on the above measurements as PESA= ALSA - RSA.

4. The number of sites around the tooth that was affected by BOP is then entered into the designated cells in the worksheet. The PISA for a particular tooth is automatically generated by multiplying PESA by the number of sites with BOP. The sum of all individual PISAs around individual teeth is calculated, amounting to the total PISA within a patient's mouth.

Statistical Analysis: The collected data were analyzed using Statistical Package for Social Sciences (SPSS) 22.0, (SPSS Inc., Chicago, IL, USA) as well as descriptive and analytical tests, including mean, standard deviation, and Independent samples t test were used.

\section{RESULTS}

In the current study table 1 shows the summary statistics for the Diabetic $(\mathrm{n}=60)$ and Non-diabetic $(n=40)$ groups. Through this study it was found that no statistically significant difference exists between these groups for age, Plaque index or ALSA.

\section{DISCUSSION}

Diabetic patients are more susceptible to gingivitis and periodontitis than healthy subjects. , $, 10,11,12_{\text {GCF }}$ glucose levels, periodontal vasculature, host response and collagen metabolism are among the proposed mechanisms by which diabetes may affect the periodontium. ${ }^{13}$ Through present study it has been clearly seen that ALSA and PISA are successful method which quantifies the condition of periodontal diseases. The most significant variable for predicting PISA in this group was Plaque index, although it accounted only to $10 \%$ of variance in PISA.

But on the other side it was found that there was no statistically significant difference present between diabetic and non-diabetic patients in case of these parameters. Till now only two studies are available that have only utilized Attachment Loss Surface Area (ALSA) or Periodontal Inflamed Surface Area (PISA) parameters that express the periodontal disease severity in truly quantitative manner. ${ }^{5,6}$ As for now, not much data is available on this topic, therefore no studies have been found for the comparison in previous literature which proved a major limitation of this study.

\section{CONCLUSION}

Within the limitations of this study it was concluded that both these markers ALSA and PISA in type 2 diabetics patients exhibited a better and quantifiable result. It has been recommended through this research that these two markers can be used clinically in order to find out the severity of diseased condition.

\section{REFERENCES}

1. All about diabetes. American Diabetes Association. Available at http://www.diabetes.org/about-diabetes.jsp. [Last Accessed December $7^{\text {th }}$, 2016.]

2. Flemmig TF. Periodontitis. Ann Periodontol 1999;4:32-8.

3. American Academy of Periodontology: Position paper. Epidemiology of periodontal diseases. J Periodontol 1996;70:1419-27.

4. Carranza AF, Newman MG, Takei H. Clinical Periodontology. 1oth ed. St.Louis; W.B.Saunders; 2006.

5. Nesse W, Abbas F, van der Ploeg I, Spijkervet FKL, Dijkstra PU, Vissink A. Periodontal inflamed surface area: quantifying inflammatory burden. J Clin Periodontol 2008;35:668-73.

6. Nesse W, Linde A, Abbas F, Spijkervet FK, Dijkstra PU, de Brabander EC, Gerstenbluth I, Vissink A. Dose-response relationship between periodontal inflamed surface area and HbAic in type 2 diabetics. J Clin Periodontol. 2009;36(4):295-300.

7. Hujoel PP, White BA, Garcia RI, Listgarten MA. The dentogingival epithelial surface area revisited. J Periodontal Res 2001;36:48-55.

8. Silness J, Loe H. Periodontal Disease In Pregnancy. II. Correlation Between Oral Hygiene And Periodontal Condtion. Acta Odontol Scand 1964;22:121-35.

9. Nelson R G, Shlossman M, Budding L M, Pettitt D J, Saad M F, Genco R J, and Knowler W C. Periodontal disease and NIDDM in Pima Indians. Diabetes Care 1990;13:836-40.

10. Cianciola LJ, Park BH, Bruck E, Mosovich L, Genco RJ. Prevalence of periodontal disease in insulin - dependent diabetes mellitus 
(juvenile diabetes). J Am Dent Assoc 1982;104(5):653-60.

11. Cohen DW, Friedman LA, Shapiro J, Kyle GC, Franklin S. Diabetes mellitus and periodontal disease: two-year longitudinal observations. I. J Periodontol. 1970;41(12):709-12.

12. Gensini GF, Modesti PA, Lopponi A, Collela A, Costagli G, Monini M. Diabetic disease and periodontal disease. Diabetes and periodontopathy. Minerva Stomatol 1992;41(9):391-9.

13. Oliver RC, Tervonen T. Diabetes--a risk factor for periodontitis in adults? J Periodontol 1994;65(5 Suppl):530-8.
Source of support: Nil, Conflict of interest: None declared

\section{Cite this article as:}

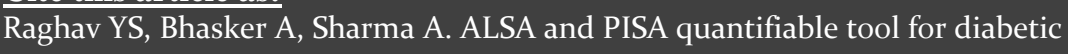
patients: A clinical study. Int Healthcare Res J 2018;2(1):16-19. doi: 10.26440/IHRJ/o2_o1/159

\section{AUTHOR AFFILIATIONS:}

1. Senior Lecturer, Department of Periodontology and Oral Implantology

2. Intern

Swami Devi Dyal Hospital and Dental College, Barwala, Panchkula, India

Corresponding Author:

Dr. Yashbir Singh Raghav

Department of Periodontology and Oral Implantology

Swami Devi Dyal Hospital and Dental College, Barwala,

Panchkula, India- 134118
For article enquiry/author contact details, e-mail at: manuscriptenquiry.ihrj@gmail.com

\section{LEGENDS}

\begin{tabular}{|c|c|c|c|c|c|}
\hline Parameter & Group & Med & SE & SD & P \\
\hline Age (years) & D & 52 & 0.694 & 5.38 & $\begin{array}{c}\text { 0.09 } \\
(\mathrm{NS})^{\dagger}\end{array}$ \\
\hline $\begin{array}{c}\text { Duration } \\
\text { (years) }\end{array}$ & ND & 49 & 1.082 & 6.84 & - \\
\hline Plaque Index & D & 7 & 0.475 & 3.68 & - \\
& ND & 1.23 & 0.078 & 0.61 & 0.32 \\
\hline ALSA & D & 1.23 & 0.062 & 0.39 & $(\mathrm{NS})^{\dagger}$ \\
\hline PISA & ND & 2071 & 65.27 & 505.6 & 0.91 \\
& D & 2083 & 94.31 & 596.5 & $(\mathrm{NS})^{\dagger}$ \\
\hline & ND & 981 & 68.08 & 527.7 & 0.35 \\
& & 1172 & 83.13 & 525.8 & $(\mathrm{NS})^{\ddagger}$ \\
\hline
\end{tabular}

Table 1. Summary statistics for the Diabetic $(n=60)$ and Non-diabetic $(n=40)$ groups

D- Diabetic, ND - Non-diabetic, CI - Confidence Interval, Med - Median, SE -

Standard Error, SD - Standard Deviation, p - Probability value (two-tailed), NS -

Non-significant, ${ }^{* * *}$ - $\mathrm{P}<0.001^{\dagger}$ - Unpaired $\mathrm{t}$ test, ${ }^{\ddagger}$ - Mann-Whitney $\mathrm{U}$ test 